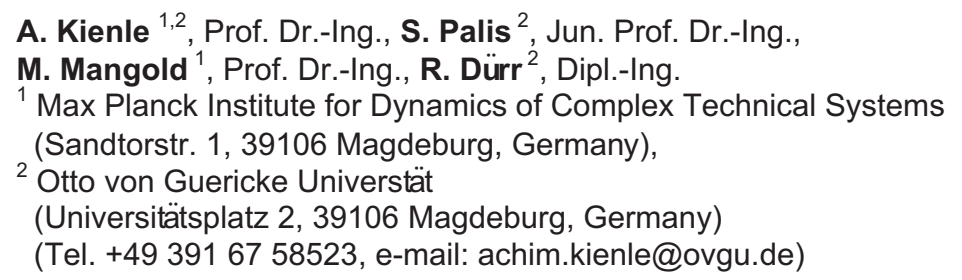

\title{
Modeling and Simulation of Particulate Processes
}

Particulate processes can be modeled by means of populations balances. This is an important class of nonlinear partial differential equations with many applications in chemical and biochemical engineering. Major challenges are multidimensional problems, coupling with nonideal flow fields and feedback control. Possible solution approaches to these problems are presented and illustrated with different types of process applications including fluidized bed spray granulation, crystallization and influenza vaccine production processes.

Процессы в макрочастицах можно моделировать, используя популяционный баланс.Он представляет собой важный класс нелинейных дифференциальных уравнений в частных производных и широко применяеься в химической и биохимической инженерии. Основными проблемами при этом являются многомерные задачи, взаимосвязь с неидеальными полями течения и управление с обратными связями. В работе представленны возможные подходы к решению этих задач на примере различных процессов, таких как грануляция в кипящем слое, кристализация и процессы производства вакцин от гриппа.

K e y w o r d s: partial differential equations, population balances, control, model reduction, proper orthogonal decomposition, direct quadrature method of moments.

Introduction. Particulate products like crystals, granules, and powders play a major role in process industries. Typical examples are pharmaceuticals, detergents, pigments, polymers etc. They represent about $60 \%$ of the produced value in the chemical industry. Typical production processes comprise crystallization, granulation, and polymerization among others. Function and effectiveness of particulate products often depend on particle properties - such as size, porosity, morphology or composition. Main objective of our research in this field of application is to devise new methods and tools for modeling, simulation and control of particulate processes aiming at the directed adjustment of desired product properties.

This is a challenging issue due to nonuniformity of particle systems, where particles differ with respect to individual properties, and product properties are

(c) A. Kienle, S. Palis, M. Mangold, R. Dürr, 2016 


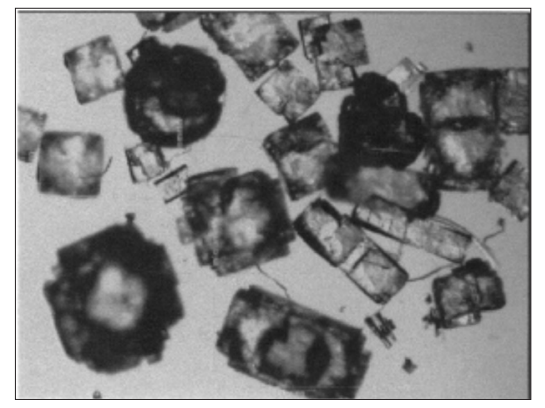

Fig. 1. Crystallization process

represented by the collective behavior of the particle population. From the theoretical point of view particulate processes belong to a special class of distributed parameter systems, so called population balance systems. They are described by nonlinear partial differential equations (PDE) often coupled to integro differential equations describing the surrounding medium (see e.g. [1]).

The paper will address main challenges for modeling, simulation and control of particulate processes and present recent solution approaches developed in our group at the Max Planck Institute and the Otto von Guericke University in Magdeburg. Theoretical concepts will be illustrated with practical application examples including granulation, crystallization and vaccine production in cell cultures.

Modeling of particulate processes. The generic structure of particulate processes is illustrated in Fig. 1 for a crystallization process. It consists of a continuous phase - also sometimes called the medium - and a disperse particle phase, which interacts with the continuous phase through an exchange of mass, energy and momentum.

Particles are characterized by their specific properties like particle size, morphology or composition, for example. These properties are summarized in a vector of internal coordinates $\mathbf{x}$. Typically, particles are nonuniform (see also Fig. 1) giving rise to a property distribution like a particle size distribution, for example. In case of spatial inhomogeneity of the continuous phase an additional vector of external space coordinates $\mathbf{r}$ is required for the mathematical description of the system. Kinetic processes in the particle phase may comprise nucleation, i.e. formation of new particles, particle growth, aggregation and breakage processes.

Microscopic models based on discrete element methods are computationally very expensive and therefore currently not well suited for model based process design and process control purposes [2]. Therefore, focus in this paper is on a more macroscopic approach using population balances [1]. In general form the population balance equation reads

$$
\frac{\partial}{\partial t} n(\mathbf{x}, \mathbf{r}, t)+\nabla_{\mathbf{r}}(\dot{\mathbf{r}} n)+\nabla_{\mathbf{x}}(\dot{\mathbf{x}} n)=\int_{d V_{\mathbf{x}}} h^{ \pm}\left(\mathbf{x}, \mathbf{x}^{\prime}, \mathbf{r}, t\right) d V_{\mathbf{x}^{\prime}}+\sum_{i} \dot{n}_{i, \text { in }}-\sum_{i} \dot{n}_{i, \text { out }},
$$

where $n(\mathbf{x}, \mathbf{r}, t)$ is a number density, which depends on external and internal variables and evolves over time. The equation consists of an accumulation term, 


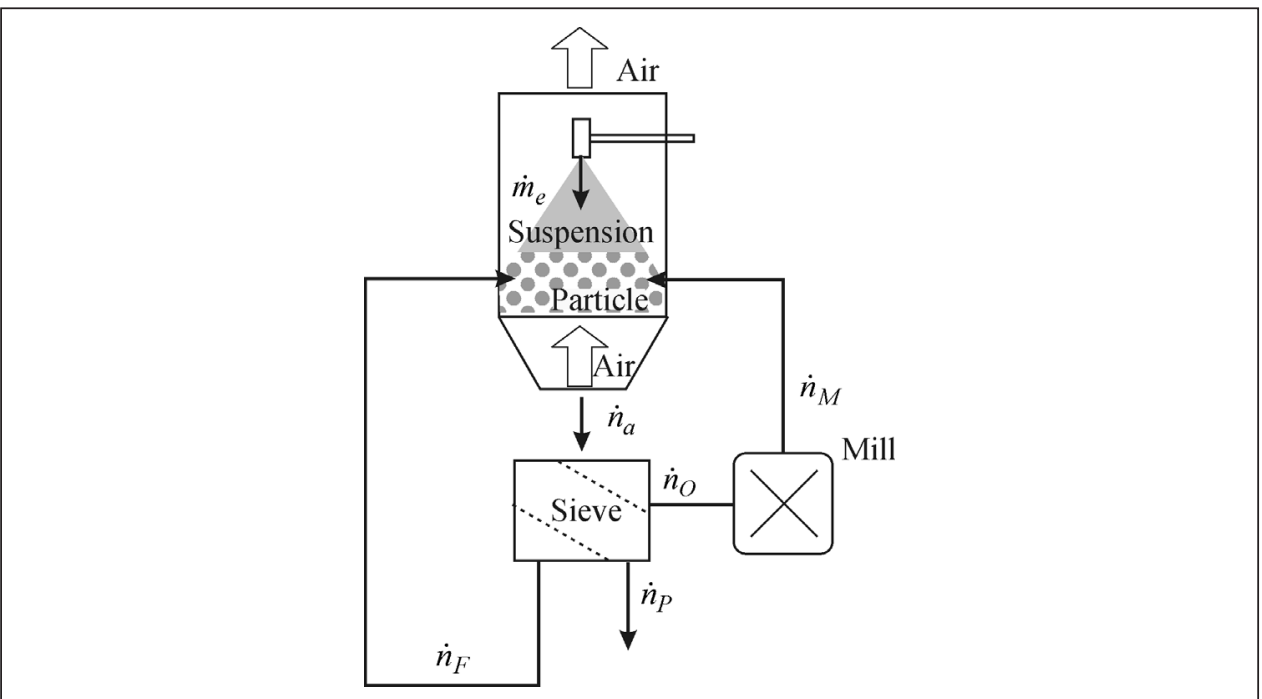

Fig. 2. Fluidized bed spray granulation process with external product classification

convection in the direction of the external (space) variables $\mathbf{r}$ and convection in the direction of the internal state variables $\mathbf{x}$. The latter corresponds to the kinetic processes contributing to the continuous change of particle properties like growth processes, for example. The convolution type of integral on the right hand side represents aggregation and breakage processes. Furthermore, material transport across the system boundaries is taken into account. The population balance is coupled with corresponding material, energy and momentum balances of the continuous phase, including spatial gradients in $\mathbf{r}$ and integral interaction with the particle phase. Specific examples will be given later in this paper.

Major challenges to be discussed subsequently comprise:

- problems with multiple internal coordinates;

- coupling with nonideal flow fields leading to problems with internal and external coordinates;

- process control.

Nonlinear dynamics and control of fluidized bed spray granulation processes. First, focus is on process control. As an application example continuous fluidized bed spray granulation as illustrated in Fig. 2 is considered. The process consists of a granulation chamber, where the particles are fluidized with a stream of hot air. From the top a liquid suspension is sprayed onto the particles giving rise to particle growth. Particles are removed continuously from the granulation chamber and classified into a product fraction, fractions of undersized and oversized particles. Oversized particles are ground with a mill and returned to- 


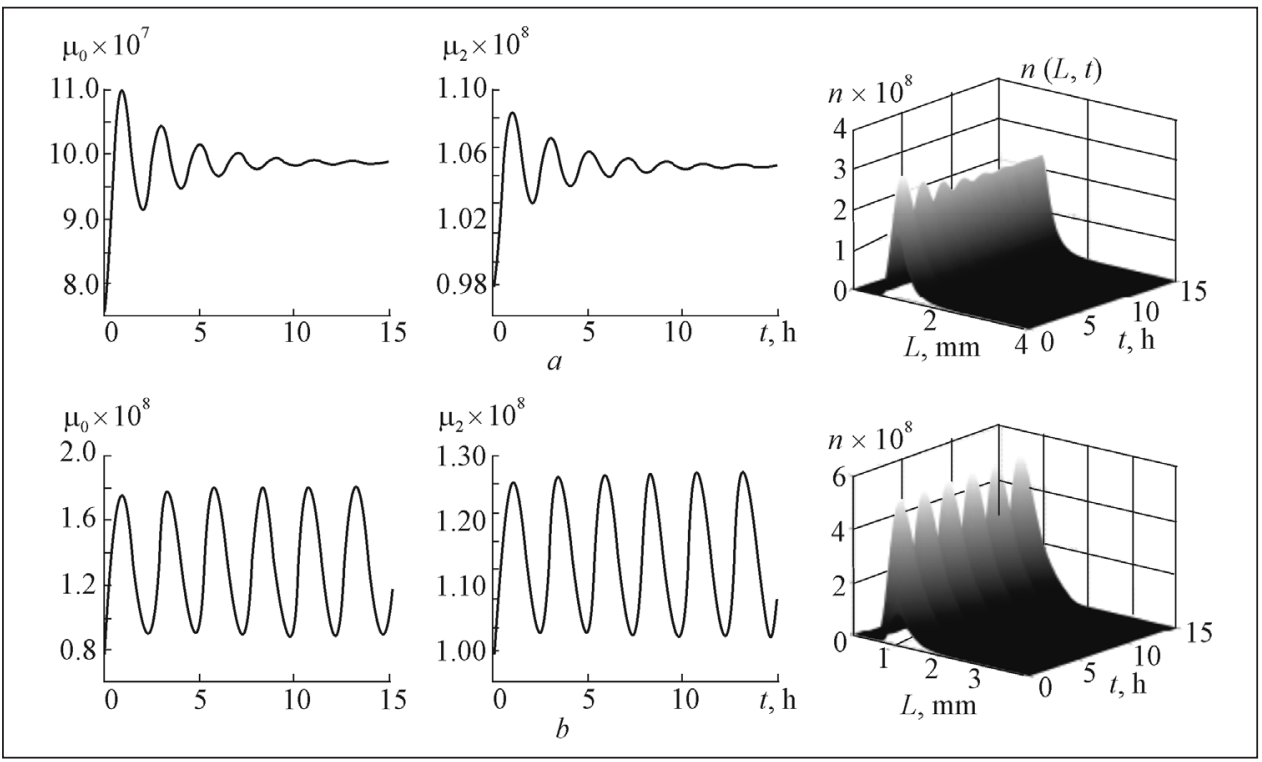

Fig. 3. Open loop simulation results: $a-$ stable (coarse grinding with $\mu_{M}=0.9 \mathrm{~mm}$ ); $b-$ unstable (fine grinding with $\mu_{M}=0.7 \mathrm{~mm}$ )

gether with the undersized particles to the granulation chamber giving rise to new nuclei for particle growth. On the one hand, this mode of operation is very economic since it avoids the supply of external nuclei. On the other hand, it may lead to dynamic instability in the from of self sustained oscillations [3]. This implies oscillating product properties like particle size $L$, which is usually not acceptable from the practical point of view. Therefore, a new method was developed for stabilization by means of feedback control.

The model equations are given by:

$$
\begin{gathered}
\frac{\partial n}{\partial t}=-G \frac{\partial n}{\partial L}-\dot{n}_{P}-\dot{n}_{O}+\dot{n}_{M}\left(\mu_{M}\right), \\
\dot{n}_{P}=T_{2}(L)\left(1-T_{1}(L)\right) \dot{n}_{\alpha}, \\
\dot{n}_{O}=T_{1}(L) \dot{n}_{\alpha},
\end{gathered}
$$

with growth rate

$$
G\left(\dot{m}_{e}\right)=\frac{2 \dot{m}_{e}}{\rho \pi \int_{0}^{\infty} L^{2} n d L}
$$




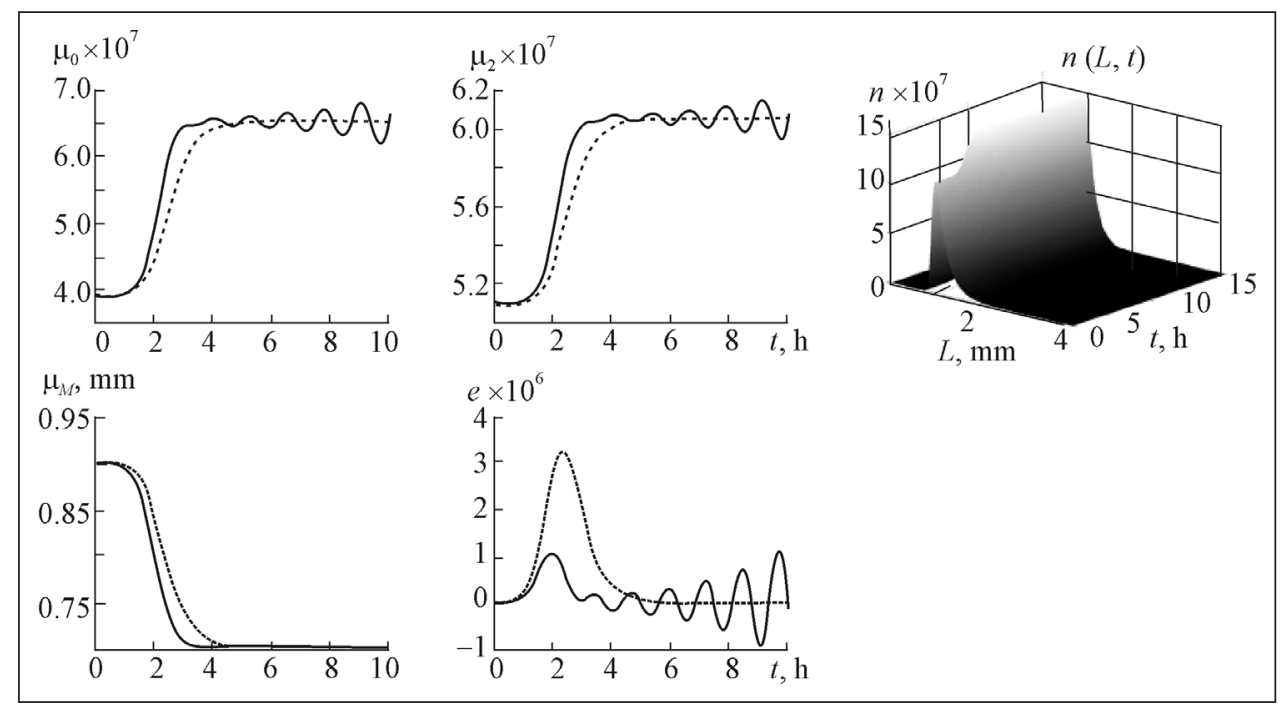

Fig. 4. Closed loop simulation results: — without control; $\cdots$ with control

which assumes that the injected liquid suspension $\dot{m}_{e}$ is equally distributed over the available total particle surface. The withdrawal $\dot{n}_{\alpha}$ follows from a total material balance assuming constant bed mass. $T_{1}(L)$ and $T_{2}(L)$ are the sigmoid classifying functions of the sieves. For the nomenclature of the flow rates $\dot{n}_{P}, \dot{n}_{O}, \dot{n}_{\alpha}$ we refer to Fig. 2.

Although the model is rather simple it contains all necessary ingredients to reproduce the nonlinear oscillations. It further shows the important influence of the mill grade $\mu_{M}$ on process stability as illustrated in Fig. 3. For coarse milling the process is settling down to a stable steady state. In contrast to this, the fine milling triggers instability [4]. This further indicates that the mill grade is a suitable handle to stabilize the process by means of feedback control.

For the present class of processes a new control method was developed. It is a Lyapunov type of approach based directly on the nonlinear PDE (1) and uses the mill grade as a lumped handle. Stability is proven in the integral sense, for the norm of the difference of the overall particle surface wrto to its given reference. It should be noted that this quantity is not a norm of the number density $n(L, t)$ but a weaker error measure called a discrepancy. It was shown that this integral stability implies pointwise convergence of $n(L, t)$, if the corresponding zero dynamics are stable as shown in Fig. 4 for the moments $\mu_{i}=\int_{0}^{\infty} L^{i} n(L, t) d L, i=0.2$ and the number density $n(L, t)$. The figure also shows the control error $e$ and the 
manipulated variable $\mu_{M}$. For unstable zero dynamics an additional robust parallel compensator can be used for stabilization. The details are given in [5].

The method is rather simple and intuitive and applies to a large class of problems. Application was also demonstrated for fluidized bed spray granulation with internal product classification [6], spray coating in a Wurster coater [7] and continuous crystallization [8]. Experimental validation is in progress.

Nonlinear model reduction for particulate processes with nonideal flow fields. Models are becoming more involved, when spatial inhomogeneities play a major role leading to problems with internal and external coordinates. A typical example is the crystallization process in a tube described in [9]. Model equations are given by the population balance coupled to the Navier Stokes equation, i.e. the momentum balance, as well as energy and material balances of the continuous phase. Internal coordinate is again the particle size $L$ which is complemented with two external coordinates summarized in the vector $\mathbf{r}$ to describe the spatial position in the crystallizer.

These kinds of models are usually too complex for online applications in the process control or process design. Therefore, nonlinear model reduction is inevitable. Proper orthogonal decomposition was used for the first time for this class of processes in $[9,10]$. The main idea is to approximate the solution of the coupled system of equations by means of a series expansion

$$
n(L, \mathbf{r}, t)=\sum_{i=1}^{n} \varphi_{i}(t) \psi_{i}(L, \mathbf{r})
$$

with basis functions $\psi_{i}$ which depend on external and internal coordinates only and time dependent weights $\varphi_{i}$. The basis functions were generated from offline simulations with the full reference model using a finite element approach. The reduced model equations for the time dependent weights were obtained by Galerkin projection. Best point interpolation was used for the approximation of nonlinearities to avoid expensive online evaluation of multidimensional integrals during runtime. With this approach the system order could be reduced by four orders of magnitude compared to the discretized PDE reference model. The computation time for online application could be reduced by three orders of magnitude, once expensive offline calculations are completed.

Recent work is concerned with automatic generation of reduced order models by means of proper orthogonal decomposition [11]. As an application a novel type of fluidized bed crystallizer as described in $[12,13]$ is considered among others.

Multidimensional modeling of influenza vaccine production processes. The third application example is concerned with biotechnological processes for 
the production of influenza vaccines. Virus influenza is a serious disease killing many people every year. Vaccination is currently the best option to protect against infection. Since influenza viruses are changing continuously, flexible production processes are required. Therefore production in mammalian cell cultures is becoming more and more important [14]. In this type of process, first a culture of mammalian cells is grown. At the begin-

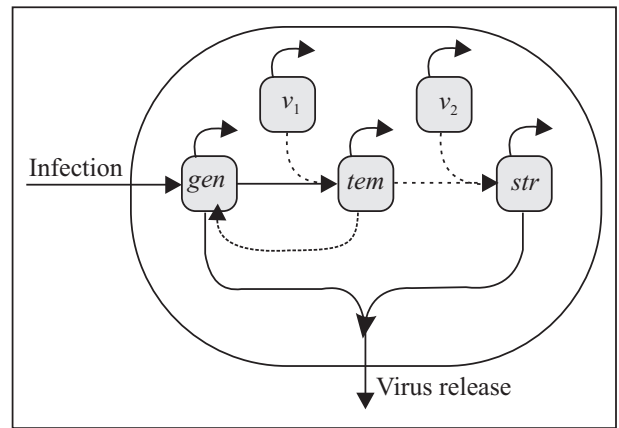

Fig. 5. Scheme for viral replication on the single cell level ning of the production process the cell culture is infected with virus seeds. Typically, in technical production processes, the amount of virus is low compared to the number of cells in the culture. Therefore in the beginning of the process only a part of the cells is infected. The virus replicates inside the infected cells and new virus is released to the medium and thereby infects step by step also the other cells. With time, active virus will also degrade and exhausted cells will die. The production process is stopped when the virus yield goes through a maximum. Then the bioreactor is harvested and the vaccine can be produced from the virus yield.

As indicated by measurements with flow cytometry the cell to cell variability is a major feature of this process which is addressed here with distributed population balance models [15]. For this purpose two different approaches are available:

1. Top down approach using global kinetics for virus infection, virus replication and virus release, which are fitted to experimental data using an inverse problem approach $[15,16]$.

2. Bottom up approach starting from detailed single cell kinetics.

The latter accounts in more detail for available biological knowledge and therefore provides more insight into the underlying biological processes and their interaction. Dynamics on the single cell level are described by a vector of physiologically relevant components such as a viral genome or viral proteins, which change over time. Since the amount of these quantities differs from cell to cell, these state variables on the single cell level translate into internal coordinates on the population level leading to multidimensional population balance equations. External coordinates are neglected here due to perfect mixing of the medium in the bioreactor.

Numerical solution of multidimensional population balance models of cellular systems can be very challenging, if $N$ the number of internal coordinates is 
large. Standard discretization techniques using finite differences, finite volumes or finite elements are typically limited to $N$ in the order of 5. Monte Carlo simulation which is another popular solution method in this field is typically limited to $N$ in the order of 10. For higher dimensional problems a new quadrature method of moments was developed. It combines monomial cubatures with the method of characteristics $[17,18]$. With this approach the computational costs increase only polynomially with $N$, in the simplest case even only linearly. For large $N$, this is a drastic reduction in computational costs compared to standard Gaussian cubatures, where the computational costs increase exponentially with $N$.

In the remainder, application is demonstrated for a relatively simple five dimensional problem, which was adopted from [19] and modified slightly. The replication kinetics are illustrated in Fig. 5. Relevant species are the viral genome gen, the template of the viral genome tem, which is used for synthesizing new genome and structural proteins str. Generation of template and structural proteins is catalyzed by viral enzymes $v_{1}$ and $v_{2}$. Viral genome and structural proteins are merged to build new viruses which are released to the medium.

The model equations are.

- Infected cells

$$
\frac{\partial i_{c}(t, \mathbf{x})}{\partial t}=-\nabla_{\mathbf{x}}\left\{\dot{\mathbf{x}} i_{c}(t, \mathbf{x})\right\}+k_{\mathrm{inf}} U_{c}(t) V(t) I(\mathbf{x})-k_{\mathrm{cd}, i_{c}}(\mathbf{x}) i_{c}(t, \mathbf{x}),
$$

where $\dot{\mathbf{x}}$ in the first term on the r.h.s. corresponds to the reaction rates on the single cell level according to

$$
\dot{\mathbf{x}}=\left(\begin{array}{c}
k_{1}\left[v_{1}\right][\text { gen }]-k_{6}[\text { tem }] \\
k_{3}[\text { tem }]-k_{1}\left[v_{1}\right][\text { gen }]-k_{5}[\text { gen }][\text { str }]-k_{7}[\mathrm{gen}] \\
k_{2}[\text { tem }]\left[v_{2}\right]-k_{4}[\text { str }]-k_{5}[\text { gen }][\text { str }] \\
f_{v_{1}} \\
f_{v_{2}}
\end{array}\right) .
$$

The second term on the r.h.s of equation (2) corrpesponds to infection and is proportional to the number of uninfected cells and the number of free viruses. The third term corresponds to cell death.

- Uninfected cells

$$
\frac{d U_{c}(t)}{\partial t}=-k_{\mathrm{inf}} U_{c}(t) V(t)+k_{\mathrm{gro}, U_{c}} U_{c}(t)-k_{\mathrm{cd}, U_{c}} U_{c}(t) .
$$

In contrast to the infected cells, uninfected cells $U_{c}$ and free virus $V$ are described by ordinary differential equations. The number of uninfected cells decreases due to infection and cell death. 


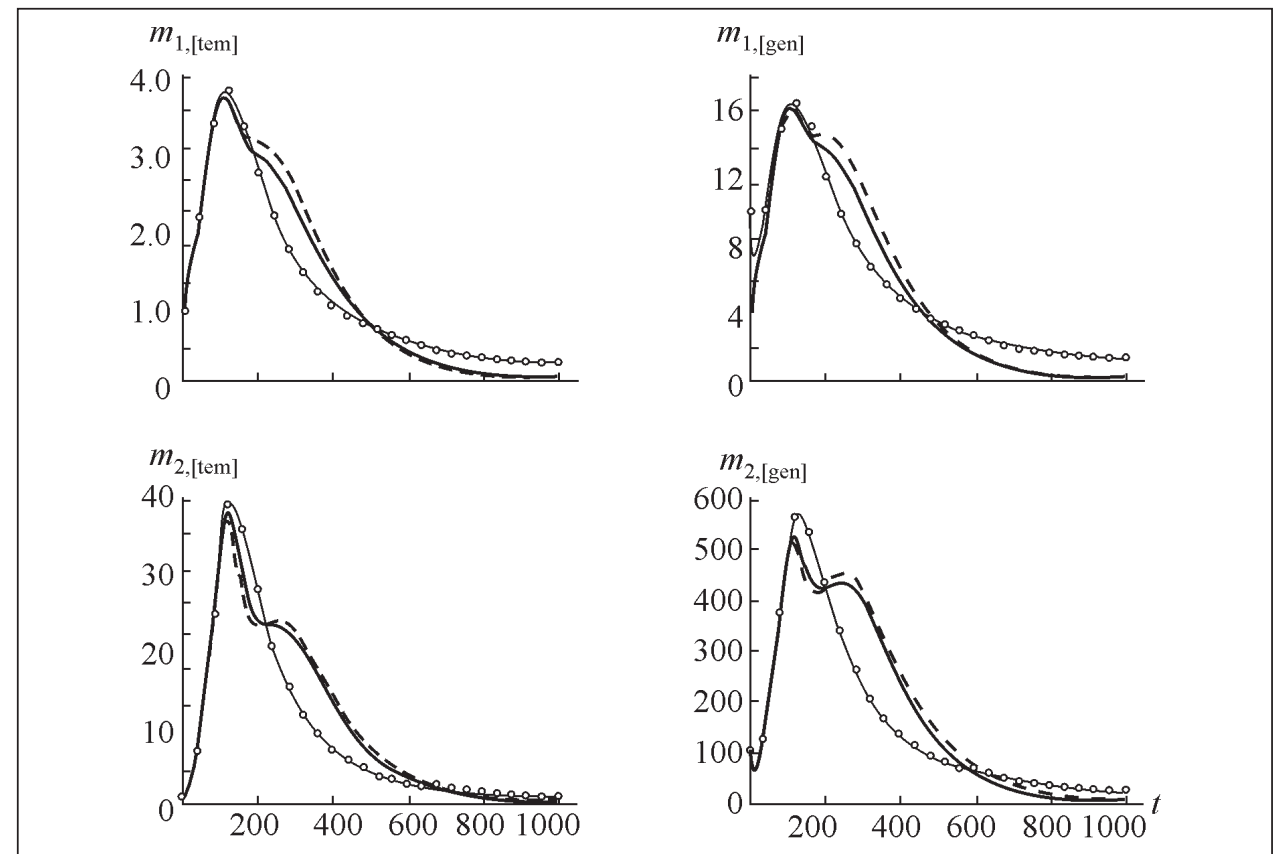

Fig. 6. Simulation results for the viral replication processes in Fig. 5: $m_{l, k}(t)=\int_{\mathbf{x}} x_{k}^{l}(\mathbf{x}) i_{c}(t, \mathbf{x}) d \mathbf{x}$;

- Monomial $\left(N_{\alpha}=66\right) ;---\operatorname{Gauss}\left(N_{\alpha}=243\right) ;-\operatorname{Monomial+GMD}\left(N_{\alpha}=121\right)$; - Monte-Carlo $\left(N_{\alpha}=10^{4}\right)$;

- Free virus in the medium

$$
\frac{d V(t)}{\partial t}=\int_{\mathbf{x}} r_{\mathrm{rel}}(\mathbf{x}) i_{c}(t, \mathbf{x}) d \mathbf{x}-k_{\mathrm{inf}} U_{c}(t) V(t)-k_{\mathrm{deg}, V} V(t)
$$

The number of free viruses increases due to release of newly formed virus from infected cells and decreases due to infection and virus degradation.

Results for the first two moments of viral genome and template are shown in Fig. 6 for different types of cubatures. The reference solution is obtained by Monte Carlo sampling with $10^{4}$ samples. Compared to a monomial and a Gaussian cubature with 66 and 243 abscissas, respectively. Both show similar performance with some deviation from the reference solution. By far the best match was obtained with a monomial cubature with mixed Gaussian model densities with 121 abscissas.

Currently the approach is applied to a detailed model of the single cell kinetics with about 30 state variables translating into 30 internal coordinates. The model aims at identifying targets or genetic modification of the cell line to im- 
prove influenza vaccine production within a joint research project with partners from academia and industry.

Conclusions. It was shown that population balance systems are an important class of distributed parameter systems with many applications in chemical and biochemical engineering. Modeling, simulation and control of population balance systems turns out to be challenging, in particular for multidimensional problems with multiple internal and/or external coordinates. Several solution approaches were presented which were developed in our research group at the Max Planck Institute and the Otto von Guericke University in Magdeburg during the last years. Nevertheless, there are still many opportunities for productive research in this field.

Acknowledgement. The financial support of the German Science Foundation within the priority program SPP 1679, the Federal Ministry for Education and Research within the projects SimParTurS (grant 03KIPAA2) and CellSys (grant 0316189A) as well as the German Competence Network of Chemical Engineering Pro3 is greatly acknowledged. Special thanks goes to Prof. Svjatnyj and his students for many years of excellent cooperation.

Процеси обробки часток можна моделювати, використовуючи популяційний баланс. Він $\epsilon$ важливим класом нелінійних диференціальних рівнянь з частинними похідними та широко застосовується в хімічній та біохімічної інженерії. Основними проблемами тут є багатовимірні задачі, взаємозв'язок з неідеальними полями течії та керування зі зворотними зв'язками. У роботі представлені можливі підходи до вирішення цих задач на прикладі різних процесів, таких як грануляція в киплячому шарі, кристалізація і процеси виробництва вакцин від грипу.

\section{REFERENCES}

1. Ramkrishna, D. (2000), Population balances: Theory and applications to particulate systems in engineering, Academic Press, New York, USA.

2. Deen, N.G., Van Sint Annaland, M., Van der Hoef, M.A. and Kuipers, J.A.M. (2007), Review of discrete particle modeling of fluidized beds, Chem. Engng. Sci., Vol. 62, pp. 28-44.

3. Heinrich, S., Peglow, M., Ihlow, M., Henneberg, M. and L. Mörl, L. (2002), Analysis of start-up process in continuous fluidized bed spray granulation by population balance modeling, Chem. Engng. Sci., Vol. 57, pp. 4369-4390.

4. Radichkov, R., Müller, T., Kienle, A., Heinrich, S., Peglow, M. and Mörl, L. (2006), A numerical bifurcation analysis of fluidized bed spray granulation with external classification, Chem. Engng. Proc., Vol. 45, pp. 826-837.

5. Palis, S. and Kienle, A. (2014), Discrepancy based control of particulate processes, J. Proc. Contr., Vol. 24, pp. 33-46.

6. Palis, S. and Kienle, A. Discrepancy based control of continuous fluidized bed spray granulation with internal product classification, Proc. 8th IFAC International Symposium on Advanced Control of Chemical Processes, Singapore, July 10-13, 2012, pp. 756-761.

7. Palis, S., Bück, A. and Kienle, A. (2013), Discrepancy based control of systems of population balances, Proc. 1st IFAC Workshop on Control of Systems Modeled by Partial Differential Equations, Paris, September 25-27, 2013, pp. 172-176. 
8. Palis, S. and Kienle, A. (2012), Diskrepanz basierte Regelung der kontinuierlichen Flüssigkristallisation, AT-Automatisierungstechnik, Vol. 60, pp. 145-154.

9. Krasnyk, M., Mangold, M., Ganesan, S. and L. Tobiska, L. (2012), Numerical reduction of a crystallizer model with internal and external coordinates by proper orthogonal decomposition, Chem. Engng. Sci., Vol. 70, pp. 77-86.

10. Krasnyk, M., Mangold, M. and Kienle, M. (2010), Extensions of the POD model reduction to multi-parameter domains, Chem. Engng. Sci., Vol. 65, pp. 6238-6246.

11. Khlopov, D. and Mangold, M. (2015), Automatic model reduction of linear population balance models by proper orthogonal decomposition, Proc. Vienna Conference on Mathematical Modeling, Vienna, February 18-20, DOI 10.1016/j.ifacol.2015.05.019, 2015.

12. Mangold, M., Feng, L.H., Khlopov, D., Palis, S., Benner, P., Binev, D. and Seidel-Morgenstern, A. (2015), Nonlinear model reduction of a continuous fluidized bed crystallizer, $J$. Comp. Appl. Math., Vol. 89, pp. 253-266.

13. Mangold, M., Khlopov, D., Danker, G., Palis, S., Sviatnyi, V. and Kienle, A. (2014), Development and nonlinear analysis of dynamic plant models in ProMoT/DIANA, ChemieIng.-Techn., Vol. 86, pp. 1-12.

14. Genzel, Y. and Reichl, U. (2009), Continuous cell lines as a production system for influenza vaccines, Expert Rev. Vaccines, Vol. 8, pp. 1681-1692.

15. Müller, T., Dürr, R., Isken, B., Schulze-Horsel, J., Reichl, U. and Kienle, A. (2013), Distributed modeling of human influenza a virus-host cell interactions during vaccine production, Biotechnol. Bioengng., Vol. 110, pp. 2252-2266.

16. Dürr, R., Müller, T., Isken, B., Schulze-Horsel, J., Reichl, U. and Kienle, A. (2012), Distributed modeling and parameter estimation of influenza virus replication during vaccine production, Proc. Vienna Conference on Mathematical Modeling, Vienna, February 15-17, 2012.

17. Dürr, R. and Kienle, A. (2014), An efficient method for calculating the moments of multi- dimensional growth processes in population balance systems, Can. J. Chem. Eng., Vol. 92, pp. 2088-2097.

18. Dürr, R., Müller, T. and Kienle, A. (2015), Efficient DQMOM for multivariate population balance equations and application to virus replication in cell cultures, Proc. Vienna Conference on Mathematical Modeling, Vienna, February 18-20, DOI 10.1016/j.ifacol.2015. 05.045, 2015.

19. Haseltine, E.L., Yin, J. and Rawlings, J.B. (2005), Dynamics of viral infections: incorporating both the intracellular and extracellular levels, Comput. Chem. Engng., Vol. 29, pp. 675-686.

Received 13.06.16 
